Accident Analysis \& Prevention, Volume 106, September 2017, Pages 23-30

DOI:10.1016/j.aap.2017.05.016

\title{
Gender roles, sex and the expression of driving anger
}

M.J.M. Sullman ${ }^{1}$, J. Paxion ${ }^{2}, \&$ A. N. Stephens ${ }^{3}$

Corresponding author

${ }^{1}$ Driving Research Group, Cranfield University, Bedfordshire, MK43 0AL, UK

M.Sullman@cranfield.ac.uk, telephone +44 1234750111 x5178

${ }^{2}$ Laboratory of Industrial and Human Automation control, Mechanical engineering and

Computer Science, Valenciennes University, Valenciennes, France

${ }^{3}$ Monash University Accident Research Centre, Melbourne Australia 


\begin{abstract}
The present study investigated the validity of the 25-item Driving Anger Expression Inventory (DAX) as well as the role of sex and gender-roles in relation to the expression of driving anger in a sample of 378 French drivers (males $=38 \%, M=32.9$ years old). Confirmatory Factor Analysis supported the four-factor structure of the 25-item DAX (Adaptive/Constructive Expression; Use of the Vehicle to Express Anger; Verbal Aggressive Expression and Personal Physical Aggressive Expression) and two of the three aggressive factors were found to have significant positive relationships with driving anger, while adaptive/constructive expression was negatively related to driving anger. Use of the vehicle to express anger was not significantly related to crash involvement, but was significantly related to all other crash-related conditions (traffic tickets, loss of concentration, loss of control of the vehicle, near crash). The presence of feminine traits, but not sex, was predictive of adaptive/constructive behaviours, while masculine traits predicted more frequent verbal aggressive expression, use of the vehicle to express anger, personal physical aggressive expression and total aggressive expression. This finding may account for the inconsistent relationship found between driving anger and sex in previous research. This research also found that the 25-item DAX is a valid tool to measure the expression of driving anger and that the endorsement of masculine traits are related to more aggressive forms of driving anger expression.
\end{abstract}

Keywords: Driving anger; Anger; Anger expression; France; gender-role; sex 


\section{Introduction}

Anger has been shown to play a substantial role in risky and aggressive driving and has been recognised to be a contributor to motor vehicle collisions (Deffenbacher, Deffenbacher, Lynch \& Richards, 2003; Ellison-Potter, Bell \& Deffenbacher, 2001; Goehring, 2000; Neighbors, Vietor \& Knee, 2002; Pickford, 2004; Smart \& Mann, 2002b; Stephens \& Sullman, 2015; Sullman, 2006). In particular, simulator research has found that anger degrades driving performance, in that angry drivers: drive faster, take longer to respond to hazards, follow lead vehicles more closely, and cross more yellow and/or red traffic lights (e.g., Abdu, Shinar \& Meiran, 2012; Mesken, Hagenzieker, Rothengatter \& De Waard, 2007; Stephens \& Groeger, 2009; Stephens \& Groeger, 2014; Stephens, Trawley, Madigan \& Groeger, 2012).

Although there is now a large body of research investigating the types of situations that provoke transitory anger (see Deffenbacher, Stephens \& Sullman, 2016 for a review), far less research has looked at the way in which drivers express anger while driving. However, the most commonly used measure of the expression of driving anger is the Driving Anger Expression Inventory (DAX), which was developed by Deffenbacher and his colleagues (Deffenbacher et al., 2002). The original 49-item DAX was refined by Stephens and Sullman (2014) to a 25-item scale which was comprised of the original four factors: Verbal Aggressive Expression (VAE); Personal Physical Aggressive Expression (PPAE); Use of the Vehicle to Express Anger (UoV); and Adaptive/Constructive Expression (A/C). A number of studies have also included an overall measure of aggressive expression (Total Aggressive Expression), which is comprised of all items from the three aggressive forms of anger expression (VAE, PPAE and UoV).

Although the 25-item version of the DAX is relatively recent, it has been validated in Spain (Gras et al., 2016), Ukraine (Sullman, Stephens \& Hill, 2016), along with the Republic of Ireland and the UK (Stephens \& Sullman, 2014). All of these studies have supported the fourfactor structure of the DAX, as have most of the studies using the 49-item version (i.e., Deffenbacher et al., 2002; Esiyok, Yasak \& Korkusuz, 2007; Jovanovic, Lipovac, Stanojevic \& Stanojevic, 2011; Sarbescu, 2012; Sullman, Stephens \& Yong, 2015; Sullman, Stephens \& Kuzu, 2014). Furthermore, the research using the 25-item DAX has supported the original four factors and the factors have been found to have very good internal reliability ( $\alpha=0.80-0.90$; Stephens \& Sullman, 2014).

While both versions of the DAX have been validated across a variety of countries and driving populations there has been some degree of variability regarding the relationships the DAX factors have with sex. Several studies have reported that females report more adaptive/constructive means of dealing with anger (Esiyok et al., 2007; Jovanović et al., 2011), 
while others have found no sex differences (Stephens \& Sullman, 2014; Villieux \& Delhomme, 2010). A number of studies have found that males tend to engage more often in personal physical aggressive expression (Dahlen \& Ragan, 2004; Esiyok et al., 2007), while others have found no sex differences on this factor (Björkqvist, 1994; Stephens \& Sullman, 2015). However, it is unclear whether this inconsistency is rooted in underlying differences in driving populations, sampling techniques or due to the slightly differing factor structures.

Interestingly, some researchers suggest that it is not sex that influences the likelihood of aggression but the gender-role endorsed by the driver (Ozkan \& Lajunen, 2005). Although the terms sex and gender are often used interchangeably in every day speech, and some scientific research, they are not the same. Sex is a biological fact that is the same regardless of culture. In contrast, the World Health Organisation (WHO) defines gender as "socially constructed roles, behaviours, activities, and attributes that a given society considers appropriate for men and women" (WHO, 2017). Thus, male and female are considered to be sex categories, while masculine and feminine are gender categories (WHO, 2017). Therefore, given that the definition of gender includes the types of behaviours that are appropriate for men and women, it would seem likely that gender, or sex-roles could be related to driving behaviour.

There has been surprisingly little research investigating the relationship gender has with risky and aggressive driving. Although they did not include the DAX, Ozkan and Lajunen (2005) found that masculinity was related to risky and aggressive driving behaviour. This finding is, to some extent, backed up by research in Ukraine, which found that gender-roles, not sex, predicted the expression of driving anger (Sullman, Stephens \& Hill, 2016). More specifically, the Ukrainian research found that femininity played a protective role in reducing engagement in aggressive forms of anger expression. Somewhat surprisingly, that study also found that masculinity was not related to aggressive forms of driving anger expression. However, these findings may not apply to other countries, as Ukraine is a developing country with a very different history and culture to those classified as Westernised.

The present study had two primary aims. The first aim was to validate the 25 -item version of the DAX using a novel sample of French drivers. This will involve testing the discriminant validity, by investigating the relationships the DAX factors have with crashes and crash-related conditions, and convergent validity by testing the relationships the subscales have with driving anger and road rage behaviours. The second primary aim of the present study was to investigate the relationships the resultant factors have with gender and sex, which has not been previously investigated in a westernised country. 


\section{Method}

\subsection{Participants}

A total of 378 participants (males $=145 ; 38 \%$ ) completed the questionnaire. Participants ranged in age from 18 to $79(M=32.90 \pm 15.93$; Median $=25)$ years old; had been licensed between 10 months and 58 years $(M=13.59 \pm 15.30 ;$ Median $=6.00)$ and drove from zero to $56,890(M$ $=12,738 \pm 9,800 ;$ Median $=10,000)$ kilometres per year.

\subsection{Materials}

Aggressive expression of anger: The manner in which drivers generally express their anger was measured with the 25-item four-factor revised DAX. The 25-item DAX is an abridged version of the original 49-item Driving Anger Expression Inventory (Deffenbacher at al., 2002) developed by Stephens and Sullman (2014). The 25-item DAX retains the original four-factors from the 49-item DAX, which are: Adaptive / Constructive expression (e.g., Pay closer attention to being a safe driver); Use of the Vehicle to express anger (e.g., Drive a lot faster); Verbal Aggressive Expression (e.g., Swear at the other driver aloud) and Personal Physical Aggressive Expression (e.g., Try to get out and have a physical fight). Each DAX item describes a potential reaction to feeling anger when driving (e.g., "I tell myself to ignore it") and drivers rate how often they react in this way on a four-point scale $(1=$ Almost never to $4=$ Almost always). Higher scores for each item represent stronger tendencies for each of the four types of responses. The 25-item DAX has shown good reliability with Cronbach's $\alpha$ ranging from 0.75 to 0.87 for the four subscales (Stephens \& Sullman, 2014). Convergent validity has also been shown through strong positive correlations between total aggressive expression scores and selfreported acts of aggression (Stephens \& Sullman, 2014).

Trait Driving Anger: The tendency to become angered while driving was measured with the 14-item Driving Anger Scale (DAS; Deffenbacher et al., 1994). Each of the 14 DAS items describes a potentially anger provoking situation and participants report the level of anger elicited by each on a five-point scale $(1=$ Not at all to $5=$ Very much). Scores for each item are summed to produce a final DAS score, with higher scores representing stronger tendencies to experience anger while driving. The 14-item DAS has demonstrated good internal consistency ( $\alpha=0.80$; Deffenbacher et al., 1994) and validity of the DAS has been shown through correlations with Spielberger's (1988) Trait Anger Scale (Deffenbacher et al., 1994; Sullman \& Stephens, 2013).

Gender roles: The Bem Sex-Role Inventory (BSRI), short version (Bem, 1981), was used to measure masculinity and femininity. This version of the scale consists of 20 statements that are 
designed to represent either masculine (10 items) or feminine (10 items) (i.e., I am assertive; I am sensitive) traits. Participants report, on a 7 -point scale $(1=$ Never or almost never true; $7=$ Almost always true), how true each statement is about them. The BSRI is commonly used to measure gender-roles (e.g., see Colley, Mulhern, Maltby \& Wood, 2009) and has been found to have good validity and reliability, with Cronbach's $\alpha$ ranging from 0.75 to $0.90(\mathrm{Bem}, 1981)$.

Self-reported road rage: Three items measured self-reported engagement in road rage and a further three items measured whether they had been victims of road rage. These items differed from the DAX items as they asked about extreme aggressive behaviours, such as threats of violence, attempts to damage a vehicle and attempts to hurt another driver. Participants respond to each question by reporting how many times they have experienced these behaviours from others and again reporting how many times they had engaged in these behaviours themselves. Participants reported the frequency of these extreme behaviours across the previous 12 months using a 6-point scale $(0=$ never; $5=5+)$.

Crash related conditions: Six items from the Driving Survey (Deffenbacher et al., 2002) measured how many times in the last three months drivers had: been fined or prosecuted for a driving offence (excluding parking tickets), lost concentration, lost control of their vehicle, experienced a near-crash, had a minor crash or a major crash. These were used as a measure of discriminant validity, as previous research has shown positive relationships between scores on the DAX and crash-related conditions (Deffenbacher et al., 2002; Sullman et al., 2013; Sullman et al., 2016).

\subsection{Procedure}

The questionnaire was first translated from English to French by a French native speaker and then translated from French to English by a French native who is fluent in English. A small number of minor discrepancies were addressed by consensus. The final translation was also checked for comprehension by two French drivers. Participants were recruited by contacting an independent agency who maintained a list of people interested in taking part in different types of research. The agency then passed on the details of the research and a link to the online questionnaire to those registered with the agency.

The questionnaire was posted online via Google Drive and participants were able to complete it by clicking on a link appearing in their email. Potential participants were informed that the study was about driving anger and that only drivers who held a valid French driving licence could participate, although their licence status was not directly checked. They were also 
informed that their participation was anonymous and that no reward would be forthcoming. The study was approved by the University ethics committee.

\subsection{Data handling}

There were no missing data for the scale responses. The crash variables produced very few positive responses: minor crashes $(n=35)$ and major crashes $(n=5)$, so minor and major crashes were combined into Crashes ( $\mathrm{Yes}=35, \mathrm{No}=343$ ), with some drivers reporting both minor and major crashes. This measure therefore indicates whether the driver has crashed at least once within the previous three-months.

Prior to analysis, the distribution of each variable was checked for normality. The DAS_short, DBQ Violations, Adaptive / Constructive expression, verbal aggressive expression, use of the vehicle to express anger and total aggressive expression were all within normal range (Skewness $<2$; Kurtosis $<2$ ). However, personal physical aggressive expression from the DAX was positively skewed and so were the road rage responses and crash-related conditions.

The structure of the 25-item DAX was analysed using Confirmatory Factor Analysis (CFA) conducted in AMOS v.22 for windows. The robust method of maximum likelihood (ML) and Bollen-Stine bootstrapping were performed on 2000 samples to account for the non-normally distributed data. The goodness-of-fit indices applied to confirm factor fit were the Chi-Squared $\left(\chi^{2}\right), \mathrm{S}-\mathrm{B} \chi^{2} / d f$, Comparative Fit Index (CFI), Tucker Lewis Index (TLI) and the Root Mean Square Error of Approximation (RMSEA). Permissible model fit was indicated by an $\chi^{2} / d f<5$; CFI and TLI of 0.90 or greater (see Bollen, 1989; Raykov \& Marcoulides, 2006) and an RMSEA no higher than 0.08 (MacCallum, Brown \& Sugawara, 1996). The confidence interval (CI) reporting a 90\% interval surrounding the RMSEA was also examined and the pclose significance aimed at $>.05$ was also examined.

\section{Results}

\subsection{Demographics}

Table 1 shows sex comparisons across annual kilometres travelled, age, licence tenure and preferred speeds across five different types of roads. Effect sizes of these differences are also presented (Cohen's $d$ ) and interpreted as small: $d=.20$, medium: $d=.50$ and large $d=.80$ (Cohen, 1988). Average age and length of licensing did not differ across sex. Males drove more kilometres each year than females and also preferred faster speeds on the higher speed zoned 
areas, such as the motorway, dual carriage way and winding country road. However, the average preferred speeds of males on these roads were still below the posted speed limits.

\subsection{Driving Anger Expression in France}

Table 2 shows the means and standard deviations of the DAX items. In line with previous research from drivers in different countries (Stephens \& Sullman, 2014; Sullman et al., 2013, Sullman, Stephens \& Hill, 2016) the most commonly reported items were from the Adaptive/Constructive factor. Items such as accepting there are frustrating situations on the road, deciding it's not worth getting involved in and thinking of positive solutions to deal with the situation were the most frequent types of responses reported by these French drivers. The second most common type of anger expression was through verbal aggressive means. This included making negative comments about the driver aloud and to a lesser extent swearing at the other driver. The scores for use of the vehicle to express anger and personal physical aggressive expression were low, indicating these types of behaviours are infrequent. The internal consistency of three of the four scales was acceptable, with Cronbach alpha coefficients ranging between 0.71 and 0.87 . However, the alpha for personal physical aggressive expression was less than ideal (0.51). Villieux and Delhomme (2010) also found this factor to be problematic due to the low frequency of these types of behaviours in their sample of drivers from France. To deal with this they removed the factor from their analyses.

\section{[insert tables $1 \& 2$ about here]}

\subsection{Factor structure of the DAX-25 items}

Confirmatory factor analysis (CFA) was used to confirm the four-factor structure of the 25item DAX. The 25-item DAX showed adequate fit to the data once the error terms for three items were co-varied. These were items 42 "Accept there are bad drivers on the road" and 45 "Accept there are frustrating situations", which both describe an acceptance of the current annoyance; items 23 "Pay closer attention to being a safe driver" and item 49 "Pay closer attention to other's driving to avoid accidents" which both describe a shifting of attention towards safety critical elements of the driving task; and, items 15 "Speed up to frustrate other driver" and 22 "Do to drivers what they did to me" which appear to be related to retaliation. The goodness of fit statistics were: $\chi^{2}(266)=530.35, \mathrm{p}<.001$, Bollen-Stine $\mathrm{p}<.001, \chi^{2 / \mathrm{df}}=$ $1.99, \mathrm{CFI}=.91, \mathrm{TLI}=.90, \mathrm{RMSEA}=.05 ; 90 \% \mathrm{CI}=.05-.06$; pclose $>.05$ (see Figure 1$).$ The $\chi^{2}$ and the Bollen-Stine $\mathrm{p}$ values were significant, which is common with larger samples and therefore remains acceptable (Byrne, 2000). 


\section{[insert Figure 1 about here]}

All regression coefficients were statistically significant in the model and the majority of the loadings were $>0.50(18 / 25: 72 \%)$. The composite reliabilities were acceptable and ranged from .62 to .84 . Table 3 shows the relationships between the DAX factors. Verbal aggressive expression and adaptive constructive expression shared the strongest relationship. In contrast, the relationship between use of the vehicle to express anger and adaptive constructive ways of dealing with anger factor scores was not significant.

\section{[insert Table 3 about here]}

\subsection{Relationships between the variables}

Given some of the variables were skewed, spearman correlations were used to examine the relationships between age, DAX scores, driving anger propensities and scores for the masculine and feminine traits (see Table 4). Masculine traits were positively related to all three less adaptive forms of expressing anger, while feminine traits were positively related to adaptive constructive forms of expressing anger, but not the three aggressive forms.

\section{[insert Table 4 about here]}

Mean scores for driving anger, gender roles and driving anger expression scores were compared across sex using Mann-Whitney $U$ tests. Females reported higher feminine traits $(n=233 ; M=$ 54.26; $\mathrm{SD}=9.43)$ when compared to males $(\mathrm{n}=145 ; \mathrm{M}=52.37 ; \mathrm{SD}=8.86 ; \mathrm{z}=2.37, \mathrm{p}=.018$, $\mathrm{r}=.12)$, while no significant differences were found by sex for masculine traits $(\mathrm{p}=.13)$. Males tended to report less driving anger $(\mathrm{M}=2.83 ; \mathrm{SD}=.68)$ compared to females $(\mathrm{M}=3.09 ; \mathrm{SD}=$ $.65 ; \mathrm{z}=3.76, \mathrm{p}<.001, \mathrm{r}=.19)$, but males reported more personal physical aggressive expressions of anger $(M=1.10 ; S D=.21)$ than their female counterparts $(M=1.05 ; S D=.14 ; z=3.20, p$ $=.001, \mathrm{r}=.16$ ). There were no other sex differences on the DAX variables.

\subsection{DAX by sex and gender roles}

To understand the contribution of gender role on aggressive forms of anger expression, multiple regression analyses were conducted on the parametric variables for adaptive constructive expression, verbal aggressive expression, personal physical aggressive expression and use of vehicle to express anger, as well as the total aggressive expression. 
Hierarchical stepwise regressions were conducted to examine the associations age, sex and annual mileage, trait driving anger, and gender roles have with the four types of anger expression, as well as total aggressive expression (see Table 5). Sex was coded as 0 for males and 1 for females. Annual mileage, age and sex were entered at the first step, with the DAS and gender roles being entered at the second step. Masculine traits, but not feminine traits, predicted all forms of aggressive anger expression. In contrast, adaptive constructive expression was predicted by age and feminine traits, with older drivers reporting more feminine traits and being more likely to use adaptive constructive forms of dealing with anger. Younger drivers and those reporting more masculine traits tended to report more use of the vehicle to express anger, and overall more aggressive anger expression. Males who reported more masculine traits also tended to report more personal physical aggressive expressive expression. While older drivers and those endorsing more feminine traits reported more adaptive constructive methods of responding to anger. These findings suggest that the endorsement of gender-role traits, rather than sex, predict aggressive expressions of driving anger.

\section{[insert Table 5 about here]}

\subsection{DAX by road rage and reported crashes}

Mann Whitney $U$ tests were conducted to compare scores on adaptive / constructive means of dealing with anger, verbal aggressive expression, use of vehicle to express anger, personal physical aggressive expression and total aggressive expression between drivers who, during the last three months, had or had not: been involved in a road rage incident; initiated a road rage incident; received a traffic ticket (excluding parking tickets); lost concentration while driving; lost control of the vehicle; experienced a near-crash; or had a crash (major \& minor combined). Bonferroni adjustments were made for multiple comparisons with alpha set at .001 .

Scores for the DAX did not differ between those who had been in a crash or near crash in the past three months, from those who had not. Scores for using the vehicle to express anger were higher for drivers who reported recently losing control of their vehicle, compared to those who had not lost control of their vehicle. Drivers who had initiated a road rage incident reported more verbal aggressive expression, use of the vehicle to express anger and less adaptive constructive ways of dealing with anger than those who had not initiated road rage.

\section{[insert Table 6 about here]}




\section{Discussion}

The present study has provided further evidence regarding the validity of the 25 -item version of the Driving Anger Expression Inventory (DAX), with Confirmatory Factor Analysis supporting the four-factor structure of the scale found by Stephens \& Sullman (2014). However, in contrast to the previous research using a sample of French drivers (Villieux \& Delhomme, 2010) and New Zealand drivers (Sullman, 2015), the present study supported the Personal Physical Aggressive Expression (PPAE) factor, as shown by the composite reliability score of .62 in the CFA model. Therefore, while the alpha coefficient, which is a lower bound estimate of reliability, for this factor was less than desirable, the inclusion of the PPAE factor was supported by the CFA and reliability calculated on the factor loadings. Therefore, while some researchers have found this factor to be unreliable, in our sample the measurement of PPAE was robust.

It is difficult to identify the reason(s) why the PPAE factor was not supported in the previous French research, but was supported in the present study. The two main differences between the present study and that of Villieux and Delhomme (2010) are that the present sample was substantially older (33 years old compared with 22 ) and that this sample was not sourced via a university, unlike the research of Villieux and Delhomme. However, the only other study that failed to support the PPAE factor was a randomly selected national sample of New Zealand drivers, who were not sourced via a university and had a much higher average age $(M=49$ years old) than either French study (Sullman, 2015). Therefore, it is likely that some other unmeasured variable(s) might be responsible for these dissimilar findings, such as socioeconomic status or a combination of measured and unmeasured variables.

The present study also found a significant positive relationship between masculinity and forms of aggressive anger expression. In other words, drivers high in masculinity were more likely to engage in personal physical aggressive expression and to use a vehicle to express anger. Furthermore, those high in femininity were significantly more likely to express their anger in an adaptive/constructive manner. These findings both appear to be in agreement with Ozkan and Lajunen's (2005) statement that aggression is related to gender-role, rather than sex. However, this contrasts somewhat with the findings made amongst Ukrainian drivers, which reported no relationship between masculinity and the aggressive forms of anger expression. The current study also supports previous research, which has found sex to be unrelated to the expression of driving anger (Björkqvist, 1994; Stephens \& Sullman, 2015; Sullman et al., 2016). 
In addition to the fact that Ukraine is a developing country, there may be other reasons for the differences between the findings here and those of the Ukrainian research. The average ages for females (Ukraine $\mathrm{M}=33.28 \pm 8.79$; France $\mathrm{M}=32.68 \pm 15.82$ ) and males (Ukraine $\mathrm{M}=$ $33.28 \pm 8.79$; France $M=33.26 \pm 16.75$ ) were similar, within and between countries. In contrast, licence tenure for French drivers (Males $M=14.21 \pm 15.56$; Females $M=13.21 \pm$ 15.15) appeared to be much higher than for Ukrainian drivers (Males $M=9.68 \pm 9.07$; Females $\mathrm{M}=8.44 \pm 9.62$ ). However, more pronounced was the difference in annual mileages reported by Ukrainian males $(\mathrm{M}=8,711 \pm 6,124)$, which was almost half that of French males $(\mathrm{M}=$ $16,042 \pm 11,536)$. The average annual mileage for Ukrainian males was also lower than that reported by both Ukrainian $(M=10,864 \pm 10,046)$ and French females $(M=10,682 \pm 7,898)$, although both groups of females were fairly similar. It is slightly unusual to find a sample where females report a higher annual mileage than males and this may have contributed to the absences of the relationship between masculinity and aggressive forms of anger expression.

The present research also found that those who reported having been the victims of road rage, or engaging in road rage behaviours themselves, reported significantly higher levels of verbal aggressive expression, use of the vehicle to express anger, personal physical aggressive expression and total aggressive expression. It is interesting that almost exactly the same relationships were found for those who engaged in road rage behaviour and those who were the victims of road rage behaviour. Perhaps this indicates that those who engage in road rage behaviours are also more likely to become the victims of road rage because of engaging in these types of road rage behaviours. The only difference was that those who had not personally engaged in road rage reported much higher use of adaptive/constructive.

This research also found that almost all of the crash related conditions, except crashes themselves, were significantly related to the three aggressive forms of driving anger expression. This agrees with most other research in the area (Stephens \& Sullman, 2014; Sullman et al., 2016). Although it is a little surprising that there was no relationship between any of the aggressive forms of expression and crash involvement, this is likely due to the very small number of crashes reported by the participants. Another possible reason could be that the relationship between the expression of driving anger and crashes is indirect.

\subsection{Limitations}

The present study also suffers from the usual limitations attributed to research based upon selfreported data, that being social desirability bias. However, as no names were collected and data collection was undertaken remotely the impact of social desirability bias is unlikely to have 
significantly affected the results (Lajunen \& Summala, 2003; Sullman \& Taylor, 2010). Furthermore, given the method of data collection this sample is unlikely to be representative of the general population of French drivers, as these participants actively sought to take part in research. Lastly, recall bias may also have influenced these results, as accurately reporting some of the events (e.g., number of times you have lost concentration while driving over the past three months) would have been difficult. Perhaps it would be better to recall these situations over a shorter period of time to reduce possible difficulties in recalling these events.

\subsection{Summary and Practical Implications}

In summary, the present research found that the 25-item DAX had good internal reliability, as well as discriminant and convergent validity. This finding highlights the usefulness of the shortened DAX as a tool to measure aggressive driving tendencies. This version of the DAX is considerably shorter than the commonly used 49-item DAX, making it easier to pair with other psychometric scales as well as reducing the sample size required to undertake the appropriate analyses.

Furthermore, this research also found several significant relationships exist between aggressive forms of anger expression and a number of crash related conditions (e.g. loss of concentrations, near crashes and receiving speed infringement notices). However, there was no significant relationship between the four types of anger expression and crashes. This is likely due to the very small number of crashes reported or perhaps the relationship with crashes is indirect. Therefore, further research is needed with a much large sample of drivers and a more sophisticated analysis of the relationships using structural equation modelling, to investigate whether the relationship is moderated by a third variable, such as speed choice.

Interestingly, this study found that higher levels of masculinity were predictive of more aggressive forms of driving anger expression and that higher levels of femininity were related to the adaptive/constructive approach to dealing with driving anger. Therefore, it would appear more useful for researchers to measure gender-role, rather than sex, when studying driving anger and aggressive driving.

The current study also found that those who had not engaged in road rage behaviour reported higher use of the adaptive/constructive form of anger expression. Perhaps this suggests that the use of adaptive/constructive strategies may be one method of reducing engagement in road rage or stimulating road rage amongst other drivers. However, given the cross-sectional nature of 
this research, it is not possible to clearly understand these relationships, highlighting the need for well-designed future research in this area. 


\section{References}

Abdu, R., Shinar, D., \& Meiran, N. (2012). Situational (state) anger and driving. Transportation Research Part F, 15, 575-580.

Bem, S. L. (1981). Gender schema theory: A cognitive account of sex typing. Psychological Review, 88(4), 354.

Björkqvist, K. (1994). Sex differences in physical, verbal, and indirect aggression: A review of recent research. Sex roles, 30(3-4), 177-188.

Cohen, J. (1988). Statistical Power Analysis for the Behavioral Sciences (2nd Edition). Hillsdale, NJ: Lawrence Earlbaum Associates.

Colley, A., Mulhern, G., Maltby, J., \& Wood, A. M. (2009). The short form BSRI: Instrumentality, expressiveness and gender associations among a United Kingdom sample. Personality and Individual Differences, 46(3), 384-387.

Dahlen, E.R., \& Ragan, K.M. (2004). Validation of the Propensity for Angry Driving Scale. Journal of Safety Research, 35(5), 557-563.

Deffenbacher, J. L. (2008). Anger, Aggression, and Risky Behavior on the Road: A Preliminary Study of Urban and Rural Differences. Journal of Applied Social Psychology, 38(1), 2236.

Deffenbacher, J. L., Lynch, R. S., Filetti, L. B., Dahlen, E. R., \& Oetting, E. R. (2003). Anger, aggression, risky behaviour, and crash-related outcomes in three groups of drivers. Behaviour research and therapy, 41(3), 333-349.

Deffenbacher, J.L., Lynch, R.S., Oetting, E.R., \& Swaim, R.C. (2002). The Driving Anger Expression Inventory: A measure of how people express their anger on the road. Behaviour Research and Therapy, 40(6), 717-737.

Deffenbacher, J. L., Lynch, R. S., Oetting, E. R., \& Yingling, D. A. (2001). Driving anger: Correlates and a test of state-trait theory. Personality and Individual Differences, 31(8), 1321-1331.

Deffenbacher, J.L., Oetting, E. R., \& Lynch, R.S. (1994). Development of a driving anger scale. Perceptual and motor skills, 74(1), 83-91.

Deffenbacher, J.L. Stephens, A.N \& Sullman, M.J.M (2016). Driving anger as a psychological construct: twenty years of research using the driving anger scale. Advances in Driving Anger: Transportation Research Part F

Ellison-Potter, P., Deffenbacher, P.B., \& Deffenbacher, J.L. (2001). The effects of trait driving anger, anonymity, and aggressive stimuli on aggressive driving behaviour. Journal of Applied Social Psychology, 31, 431-443. 
Eşiyok, B., Yasak, Y., \& Korkusuz, I. (2007). Anger expression on the road: validity and reliability of the driving anger expression inventory. Turk Psikiyatri Derg, 18(3), 231243.

Goehring, J. B. (2000). Aggressive driving: background and overview report.

Gras, M.E., Font-Mayolas, S., Patino, J., Baltasar, A., Planes, M., \& Sullman, M.J.M. (2016). Resilience and the expression of anger while driving. Transportation Research Part F.

Jovanović, D., Lipovac, K., Stanojević, P., \& Stanojević, D. (2011). The effects of personality traits on driving-related anger and aggressive behaviour in traffic among Serbian drivers. Transportation research part F: traffic psychology and behaviour, 14(1), 4353.

Mesken, J., Hagenzieker, M. P., Rothengatter, T., \& de Waard, D. (2007). Frequency, determinants, and consequences of different drivers' emotions: An on-the-road study using self-reports, (observed) behaviour, and physiology. Transportation Research Part $F, 10(6), 458-475$. doi:10.1016/j.trf.2007.05.001

Neighbors, C., Vietor, N. A., \& Knee, C. R. (2002). A motivational model of driving anger and aggression. Personality and Social Psychology Bulletin,28(3), 324-335.

Özkan, T., \& Lajunen, T. (2005). Why are there sex differences in risky driving? The relationship between sex and gender role on aggressive driving, traffic offences, and accident involvement among young Turkish drivers.Aggressive behavior, 31(6), 547558.

Pickford, B. W. (2004). Experiences of aggressive behavior and its effect regarding road rage. University of Michigan-Flint.

Raykov, T., \& Marcoulides, G. A. (2006). On multilevel model reliability estimation from the perspective of structural equation modeling. Structural Equation Modeling, 13(1), 130141.

Sârbescu, P. (2012). Aggressive driving in Romania: Psychometric properties of the driving anger expression inventory. Transportation research part F: traffic psychology and behaviour, 15(5), 556-564.

Smart, R. G., \& Mann, R. E. (2002b). Deaths and injuries from road rage: cases in Canadian newspapers. Canadian Medical Association Journal,167(7), 761-762.

Stephens, A. N., \& Groeger, J. A. (2009). Situational specificity of trait influences on drivers' evaluations and driving behaviour. Transportation research part F: traffic psychology and behaviour, 12(1), 29-39.

Stephens, A. N., \& Groeger, J. A. (2014). Following slower drivers: Lead driver status moderates driver's anger and behavioural responses and exonerates culpability. $\begin{array}{lllll}\text { Transportation } \quad \text { Research } & \text { Part }\end{array}$ doi:http://dx.doi.org/10.1016/j.trf.2013.11.005 
Stephens, A. N., \& Sullman, M. J. M. (2014). Development of a short form of the driving anger expression inventory. Accident Analysis \& Prevention, 72, 169-176.

Stephens, A.N., \& Sullman, M.J.M. (2015). A comparison of anger, aggression and crash related behaviours across drivers from the United Kingdom and Irish Republic. Risk Analysis, 35(9), 1730-45 DOI: 10.1111/risa.12379

Stephens, A. N., Trawley, S. L., Madigan, R., \& Groeger, J. A. (2013). Drivers Display Anger Congruent Attention to Potential Traffic Hazards. Applied cognitive psychology, 27(2), 178-189.

Sullman, M.J.M. (2006). Anger amongst New Zealand drivers. Transportation Research - Part $F, 9,173-184$.

Sullman, M.J.M. (2015). The expression of anger on the road. Safety Science, 72, 153-159. 10.1016/j.ssci.2014.08.013

Sullman, M. J., Gras, M. E., Cunill, M., Planes, M., \& Font-Mayolas, S. (2007). Driving anger in Spain. Personality and individual differences, 42(4), 701-713.

Sullman, M.J.M., Stephens, A.N. \& Hill, T. (2016) Gender roles and the expression of driving anger amongst Ukrainian drivers. Risk Analysis. 10 MAR 2016 | DOI: 10.1111/risa. 12592

Sullman, M.J.M., Stephens, A.N., \& Kuzu, D. (2013). The expression of anger amongst Turkish taxi drivers. Accident Analysis \& Prevention, 56, 42-50.

Sullman, M. J., Stephens, A. N., \& Yong, M. (2014). Driving anger in Malaysia. Accident Analysis \& Prevention, 71, 1-9.

Underwood, G., Chapman, P., Wright, S., \& Crundall, D. (1999). Anger while driving. Transportation Research Part F: Traffic Psychology and Behaviour, 2(1), 55-68.

Villieux, A., \& Delhomme, P. (2010). Driving anger and its expressions: Further evidence of validity and reliability for the Driving Anger Expression Inventory French adaptation. Journal of safety research, 41(5), 417-422.

WHO (2017). Gender, women and health: What do we mean by "sex" and "gender"?. Retrieved Jan. 20, 2017 from: http://apps.who.int/gender/whatisgender/en/

Yasak, Y., \& Esiyok, B. (2009). Anger amongst Turkish drivers: Driving Anger Scale and its adapted, long and short version. Safety science, 47(1), 138-144. 
Table 1: Age, licence history and preferred speed by sex

\begin{tabular}{|c|c|c|c|c|}
\hline Variable & Males $(N=145)$ & Females $(N=233)$ & $t(376)$ & Cohen's $d$ \\
\hline & $\begin{array}{l}\text { Average }(S D) \\
\text { Median }\end{array}$ & $\begin{array}{l}\text { Average }(S D) \\
\text { Median }\end{array}$ & & \\
\hline Annual kilometres travelled & $\begin{array}{l}16,042(11,536) \\
15,000\end{array}$ & $\begin{array}{l}10,682(7,898) \\
10,000\end{array}$ & $4.93 * * *$ & .54 \\
\hline Age (years) & $\begin{array}{l}33.26(16.15) \\
26.00\end{array}$ & $\begin{array}{l}32.68(15.82) \\
25.00\end{array}$ & $<1$ & .04 \\
\hline Length of licence (years) & $\begin{array}{l}14.21(15.56) \\
6.00\end{array}$ & $\begin{array}{l}13.21(15.15) \\
6.00\end{array}$ & $<1$ & .07 \\
\hline Preferred speed on motorway $(130 \mathrm{~km} / \mathrm{h})$ & $\begin{array}{l}128.52(10.26) \\
130\end{array}$ & $\begin{array}{l}125.61(8.78) \\
130\end{array}$ & $2.94 * *$ & .30 \\
\hline Preferred speed on busy main street $(50 \mathrm{~km} / \mathrm{h})$ & $\begin{array}{l}43.44(10.65) \\
50\end{array}$ & $\begin{array}{l}41.37(10.55) \\
40\end{array}$ & 1.85 & .20 \\
\hline Preferred speed in residential areas $(50 \mathrm{~km} / \mathrm{h})$ & $\begin{array}{l}49.03(8.47) \\
50\end{array}$ & $\begin{array}{l}47.89(7.68) \\
50\end{array}$ & 1.35 & .14 \\
\hline Preferred speed in dual carriageway $(110 \mathrm{~km} / \mathrm{h})$ & $\begin{array}{l}111.63(8.91) \\
110\end{array}$ & $\begin{array}{l}108.29(8.84) \\
110\end{array}$ & $3.56^{* * *}$ & .37 \\
\hline Preferred speed on a winding country road $(100 \mathrm{~km} / \mathrm{h})$ & $\begin{array}{l}88.06(10.91) \\
90\end{array}$ & $\begin{array}{l}82.70(10.29) \\
80\end{array}$ & $4.82 * * *$ & .51 \\
\hline
\end{tabular}

${ }^{*} \mathrm{p}<.05, * * \mathrm{p}<.006 ; * * * p<.001 ;$ Bonferroni adjustments for multiple comparisons ( $\mathrm{p}$ accepted at .006 or lower) 
Table 2: Item means for the DAX revised (25 item scale)

\begin{tabular}{lll}
\hline DAX items & $\mathrm{N}=378$ \\
& $\mathrm{M}(S D)$ \\
\hline Adaptive/Constructive Expression from DAX 25-items $(\alpha=.87)$ & $2.60(.65)$ \\
\hline 49 & Pay closer attention to other's driving to avoid accidents & $3.21(.86)$ \\
23 & Pay closer attention to being a safe driver & $2.96(.89)$ \\
45 & Accept there are frustrating situations & $2.65(.90)$ \\
42 & Accept there are bad drivers on the road & $2.57(.96)$ \\
36 & Tell myself it's not worth getting involved & $2.56(1.02)$ \\
26 & Think of positive solutions to deal with the situation & $2.55(.94)$ \\
30 & Not stoop to their level & $2.54(.94)$ \\
29 & Tell myself it's not worth getting mad at & $2.47(1.04)$ \\
48 & Tell myself to ignore it & $2.46(.95)$ \\
35 & Think of positive things to do & $2.16(1.01)$ \\
\hline Verbal Aggressive Expression $(\alpha=.76)$ & $2.03(.65)$ \\
\hline 6 & Make negative comments about the driver aloud & $2.46(.79)$ \\
28 & Swear at the other driver aloud & $2.00(.97)$ \\
5 & Call the other driver names aloud & $2.04(.89)$ \\
31 & Swear at the other driver under my breath & $1.96(.96)$
\end{tabular}


38 Yell at the other driver

$1.73(.95)$

Use of Vehicle to Express Anger $(\alpha=.71)$

27 Drive a lot faster $1.59(.77)$

15 Speed up to frustrate other driver $1.42(.69)$

2 Drive right up on the other driver's bumper $1.35(.62)$

22 Do to drivers what they did to me $1.29(.59)$

7 Follow right behind for a long time $1.19(.50)$

Personal Physical Aggressive Expression $(\alpha=.51) \quad 1.07$ (.17)

10 Roll down the window to communicate my anger $1.18(.45)$

21 Try to scare the driver $1.08(.31)$

8 Try to get out of the car and tell the other driver off $1.06(.25)$

41 Try to get out and have a physical fight $1.03(.22)$

17 Bump the driver's bumper with my own $1.01(.17)$

Total Aggressive Expression (no Adaptive items) $(\alpha=.77)$ 
Table 3: Relationships between DAX factors reported in CFA model

\begin{tabular}{llll}
\hline & Adaptive Constructive & Verbal Aggressive Expression & Use of Vehicle \\
\hline Adaptive Constructive & --- & & \\
Verbal Aggressive Expression & $-.51^{* * *}$ & -- & $-30^{* * *}$ \\
Use of Vehicle & $-.32^{* * *}$ & $.26^{* * *}$ & $.30^{* *}$ \\
Personal Physical Aggressive & -.19 & & \\
expression & & & \\
\hline
\end{tabular}

$* * * p \leq .001 ; * * p \leq .01$ 
Table 4: Intercorrelations between variables $(N=378)$ and variable means (SD)

\begin{tabular}{|c|c|c|c|c|c|c|}
\hline & 1 & 2 & 3 & 4 & 5 & 6 \\
\hline 1. Age & -- & & & & & \\
\hline 2. Years licensed & $.97 * * *$ & -- & & & & \\
\hline 3. Annual mileage & $.21 * * *$ & $.24 * * *$ & --- & & & \\
\hline 4. Masculine & $-.17 * * *$ & $-.15^{* * *}$ & .09 & --- & & \\
\hline 5. Feminine & .08 & .06 & -.03 & .05 & --- & \\
\hline 6. DAS_short & $-.16^{* *}$ & $-.15^{* * *}$ & -.05 & .09 & .03 & --- \\
\hline 7. $\mathrm{A} / \mathrm{C}$ & $.21 * * *$ & $.18 * * *$ & .04 & -.05 & $.30^{* * *}$ & $-.23 * * *$ \\
\hline 8. VAE & $-.24 * * *$ & $-.23^{* * *}$ & -.04 & $.13^{* *}$ & -.03 & $.28^{* * *}$ \\
\hline 9. $\mathrm{UoV}$ & $-.21 * * *$ & $-.17 * * *$ & -.08 & $.15^{* *}$ & -.05 & $.28 * * *$ \\
\hline 10. PPAE & .02 & .04 & $.13^{*}$ & $.24 * *$ & .08 & .10 \\
\hline 11. TAE & $-.27 * * *$ & $-.24 * * *$ & .01 & $.18 * * *$ & -.07 & $.34 * * *$ \\
\hline Means (SD) & $\begin{array}{l}32.90 \\
(15.93)\end{array}$ & $\begin{array}{l}13.59 \\
(15.30)\end{array}$ & $\begin{array}{l}12,737 \\
(9,799)\end{array}$ & $\begin{array}{l}42.08 \\
(10.12) \\
\alpha=.85\end{array}$ & $\begin{array}{l}53.53 \\
(9.24) \\
\alpha=.89\end{array}$ & $2.99(.67)$ \\
\hline
\end{tabular}


$\overline{\mathrm{A} / \mathrm{C}}=$ Adaptive Constructive; PPAE $=$ Personal Physical; VAE $=$ Verbal; UoV $=$ Use of Vehicle; DAS $=$ driving anger scale $* * * p \leq .001 ; * * p \leq .01 ; * p \leq .05$; 
Table 5: Anger expression by gender-role 


\begin{tabular}{|c|c|c|c|c|}
\hline Final Models & Variable & Adjusted $\mathrm{R}^{2}$ & Change $\mathrm{R}^{2}$ & $B$ \\
\hline \multicolumn{5}{|l|}{ Adaptive / Constructive } \\
\hline$F(1,376)=30.53, p<.001$ & Age & .08 & .08 & $.23 * * *$ \\
\hline$F(2,375)=37.70, p<.001$ & Feminine & .17 & .09 & $.32 * * *$ \\
\hline$F(3,374)=33.53, p<.001$ & DAS & .21 & .05 & $-.21 * * *$ \\
\hline \multicolumn{5}{|l|}{ Verbal expressions of anger } \\
\hline$F(1,376)=35.97, p<.001$ & Age & .09 & .09 & $-.26 * * *$ \\
\hline$F(2,375)=34.23, p<.001$ & DAS & .15 & .07 & $.26^{* * *}$ \\
\hline \multicolumn{5}{|l|}{ Use of Vehicle to express } \\
\hline \multicolumn{5}{|l|}{ anger } \\
\hline$F(1,376)=24.18, p<.001$ & Age & .06 & .06 & $-.21 * * *$ \\
\hline$F(2,375)=15.13, p<.001$ & Mileage & .07 & .01 & $.12 *$ \\
\hline$F(3,374)=21.97, p<.001$ & DAS & .14 & .08 & $.27 * * *$ \\
\hline$F(4,373)=18.18, p<.001$ & Masculine & .15 & .01 & $.12 *$ \\
\hline
\end{tabular}


Personal Physical

Expressions of anger

\begin{tabular}{lllll}
\hline$F(1,376)=9.00, p=.003$ & Gender & .02 & .02 & $-.17^{* * *}$ \\
\hline$F(2,375)=10.30, p<.001$ & DAS & .05 & .03 & $.16^{* * *}$ \\
\hline$F(3,374)=8.55, p<.001$ & Masculine & .06 & .01 & $.11^{* *}$ \\
& & & & \\
\hline
\end{tabular}

Total Aggressive Expression

\begin{tabular}{lllll}
\hline$F(1,376)=42.05, p=.003$ & Age & .10 & .10 & $-.25^{* * *}$ \\
\hline$F(2,375)=47.73, p<.001$ & DAS & .20 & .10 & $.31^{* * *}$ \\
\hline$F(3,374)=35.80, p<.001$ & Masculine & .22 & .02 & $.14^{* * *}$
\end{tabular}


Table 6: Anger expression by reported detrimental driving behaviours

\begin{tabular}{|c|c|c|c|c|c|c|c|c|c|c|c|c|c|c|c|}
\hline & \multicolumn{3}{|c|}{$\begin{array}{l}\text { Adaptive/Constructiv } \\
\text { e Expression }\end{array}$} & \multicolumn{3}{|c|}{$\begin{array}{l}\text { Verbal Aggressive } \\
\text { Expression }\end{array}$} & \multicolumn{3}{|c|}{$\begin{array}{l}\text { Use of Vehicle to } \\
\text { Express Anger }\end{array}$} & \multicolumn{3}{|c|}{$\begin{array}{l}\text { Personal Physical } \\
\text { Aggressive } \\
\text { Expression }\end{array}$} & \multicolumn{3}{|c|}{$\begin{array}{l}\text { Total aggressive } \\
\text { expression }\end{array}$} \\
\hline & $\begin{array}{l}\text { Yes } \\
\mathrm{M} \\
(S D)\end{array}$ & $\begin{array}{l}\text { No } \\
\mathrm{M} \\
(S D \\
)\end{array}$ & $\begin{array}{l}p \\
r\end{array}$ & $\begin{array}{l}\text { Yes } \\
\mathrm{M} \\
(S D)\end{array}$ & $\begin{array}{l}\text { No } \\
\mathrm{M} \\
(S D \\
)^{2} \\
\end{array}$ & $\begin{array}{l}p \\
r\end{array}$ & $\begin{array}{l}\text { Yes } \\
\mathrm{M} \\
(S D)\end{array}$ & $\begin{array}{l}\text { No } \\
\mathrm{M} \\
(S D)\end{array}$ & $\begin{array}{l}p \\
r\end{array}$ & $\begin{array}{l}\text { Yes } \\
\text { M } \\
\text { (SD } \\
\end{array}$ & $\begin{array}{l}\text { No } \\
\mathrm{M} \\
\text { (SD) }\end{array}$ & $\begin{array}{l}p \\
r\end{array}$ & $\begin{array}{l}\text { Yes } \\
\mathrm{M} \\
(\mathrm{SD})\end{array}$ & $\begin{array}{l}\text { No } \\
\text { M } \\
\text { (SD) }\end{array}$ & $\begin{array}{l}p \\
r\end{array}$ \\
\hline $\begin{array}{l}\text { Experienced } \\
\text { road rage } \\
\text { yes: } n=266 \\
\text { no: } n=112\end{array}$ & $\begin{array}{l}2.60 \\
(.65)\end{array}$ & $\begin{array}{l}2.62 \\
(.65 \\
)\end{array}$ & $\begin{array}{l}\mathrm{ns} \\
.01\end{array}$ & $\begin{array}{l}2.11 \\
(.66)\end{array}$ & $\begin{array}{l}1.85 \\
(.62 \\
)\end{array}$ & $\begin{array}{l}<.001 \\
.17\end{array}$ & $\begin{array}{l}1.39 \\
(.44)\end{array}$ & $\begin{array}{l}1.30 \\
(.41)\end{array}$ & $\begin{array}{l}<.05 \\
.12\end{array}$ & $\begin{array}{l}1.08 \\
(.16 \\
)\end{array}$ & $\begin{array}{l}1.05 \\
(.19)\end{array}$ & $\begin{array}{l}<.05 \\
.13\end{array}$ & $\begin{array}{l}1.53 \\
(.32)\end{array}$ & $\begin{array}{l}1.40 \\
(.30)\end{array}$ & $\begin{array}{l}<.01 \\
.19\end{array}$ \\
\hline $\begin{array}{l}\text { Engaged in } \\
\text { road rage } \\
\text { yes: } n=265 \\
\text { no: } n=113\end{array}$ & $\begin{array}{l}2.47 \\
(.63)\end{array}$ & $\begin{array}{l}2.92 \\
(.59 \\
)\end{array}$ & $\begin{array}{l}<.001 \\
.32\end{array}$ & $\begin{array}{l}2.23 \\
(.63)\end{array}$ & $\begin{array}{l}1.58 \\
(.46 \\
)\end{array}$ & $\begin{array}{l}<.001 \\
.47\end{array}$ & $\begin{array}{l}1.42 \\
(.46)\end{array}$ & $\begin{array}{l}1.24 \\
(.35)\end{array}$ & $\begin{array}{l}<.00 \\
1 \\
.20\end{array}$ & $\begin{array}{l}1.09 \\
(.20 \\
)\end{array}$ & $\begin{array}{l}1.03 \\
(.08)\end{array}$ & $\begin{array}{l}<.01 \\
.16\end{array}$ & $\begin{array}{l}1.58 \\
(.32)\end{array}$ & $\begin{array}{l}1.28 \\
(.22)\end{array}$ & $\begin{array}{l}<.001 \\
.47\end{array}$ \\
\hline $\begin{array}{l}\text { Traffic } \\
\text { Tickets } \\
\text { yes: } n=28 \\
\text { no: } n=350\end{array}$ & $\begin{array}{l}2.63 \\
(.61)\end{array}$ & $\begin{array}{l}2.60 \\
(.66 \\
)\end{array}$ & $\begin{array}{l}\mathrm{ns} \\
.01\end{array}$ & $\begin{array}{l}1.96 \\
(.61)\end{array}$ & $\begin{array}{l}2.04 \\
(.86 \\
)\end{array}$ & $\begin{array}{l}\mathrm{ns} \\
.01\end{array}$ & $\begin{array}{l}1.51 \\
(.46)\end{array}$ & $\begin{array}{l}1.35 \\
(.43)\end{array}$ & $\begin{array}{l}<.05 \\
.11\end{array}$ & $\begin{array}{l}1.15 \\
(.33 \\
)\end{array}$ & $\begin{array}{l}1.07 \\
(.15)\end{array}$ & $\begin{array}{l}\mathrm{ns} \\
.07\end{array}$ & $\begin{array}{l}1.54 \\
(.36)\end{array}$ & $\begin{array}{l}1.49 \\
(.32)\end{array}$ & $\begin{array}{l}\mathrm{ns} \\
.01\end{array}$ \\
\hline $\begin{array}{l}\text { Loss of } \\
\text { concentration } \\
\text { yes: } n=251 \\
\text { no: } n=127\end{array}$ & $\begin{array}{l}2.55 \\
(.63)\end{array}$ & $\begin{array}{l}2.70 \\
(.69 \\
)\end{array}$ & $\begin{array}{l}<.05 \\
.12\end{array}$ & $\begin{array}{l}2.07 \\
(.62)\end{array}$ & $\begin{array}{l}1.98 \\
(.72 \\
)\end{array}$ & $\begin{array}{l}\mathrm{ns} \\
.09\end{array}$ & $\begin{array}{l}1.41 \\
(.46)\end{array}$ & $\begin{array}{l}1.28 \\
(.38)\end{array}$ & $\begin{array}{l}<.01 \\
.16\end{array}$ & $\begin{array}{l}1.08 \\
(.18 \\
)\end{array}$ & $\begin{array}{l}1.06 \\
(.15)\end{array}$ & $\begin{array}{l}\mathrm{ns} \\
.05\end{array}$ & $\begin{array}{l}1.52 \\
(.32)\end{array}$ & $\begin{array}{l}1.43 \\
(.33)\end{array}$ & $\begin{array}{l}<.01 \\
.13\end{array}$ \\
\hline $\begin{array}{l}\text { Loss } \quad \text { of } \\
\text { control } \\
\text { yes: } n=140 \\
\text { no: } n=238\end{array}$ & $\begin{array}{l}2.50 \\
(.65)\end{array}$ & $\begin{array}{l}2.66 \\
(.65 \\
)\end{array}$ & $\begin{array}{l}<.05 \\
.13\end{array}$ & $\begin{array}{l}2.08 \\
(.62)\end{array}$ & $\begin{array}{l}2.01 \\
(.67 \\
)\end{array}$ & $\begin{array}{l}\mathrm{ns} \\
.07\end{array}$ & $\begin{array}{l}1.47 \\
(.49)\end{array}$ & $\begin{array}{l}1.30 \\
(.39)\end{array}$ & $\begin{array}{l}<.00 \\
1 \\
.20\end{array}$ & $\begin{array}{l}1.08 \\
(.20 \\
)\end{array}$ & $\begin{array}{l}1.07 \\
(.15)\end{array}$ & $\begin{array}{l}\mathrm{ns} \\
.01\end{array}$ & $\begin{array}{l}1.54 \\
(.32)\end{array}$ & $\begin{array}{l}1.46 \\
(.32)\end{array}$ & $\begin{array}{l}<.01 \\
.14\end{array}$ \\
\hline
\end{tabular}




\begin{tabular}{llllllllllllllll} 
Near crash & 2.56 & 2.65 & $\mathrm{~ns}$ & 2.09 & 1.97 & $<.05$ & 1.42 & 1.30 & $<.01$ & 1.08 & 1.06 & $\mathrm{~ns}$ & 1.53 & 1.44 & $<.01$ \\
yes: $n=205$ & $(.66)$ & $(.64$ & .08 & $(.65)$ & $(.66$ & .11 & $(.48)$ & $(.38)$ & .13 & $(.20$ & $(.14)$ & .01 & $(.34)$ & $(.29)$ & .13 \\
no: $n=173$ & & ) & & & ) & & & & & ) & & & & & \\
Crashes & 2.50 & 2.61 & $\mathrm{~ns}$ & 2.14 & 2.02 & $\mathrm{~ns}$ & 1.49 & 1.35 & $\mathrm{~ns}$ & 1.08 & 1.07 & $\mathrm{~ns}$ & 1.57 & 1.48 & $\mathrm{~ns}$ \\
yes: $n=35$ & $(.68)$ & $(.65$ & .05 & $(.76)$ & $(.64$ & .03 & $(.47)$ & $(.43)$ & .10 & $(.14$ & $(.18)$ & .05 & $(.37)$ & $(.32)$ & .06 \\
no: $n=343$ & & ) & & & ) & & & & & ) & & & & & \\
\hline
\end{tabular}




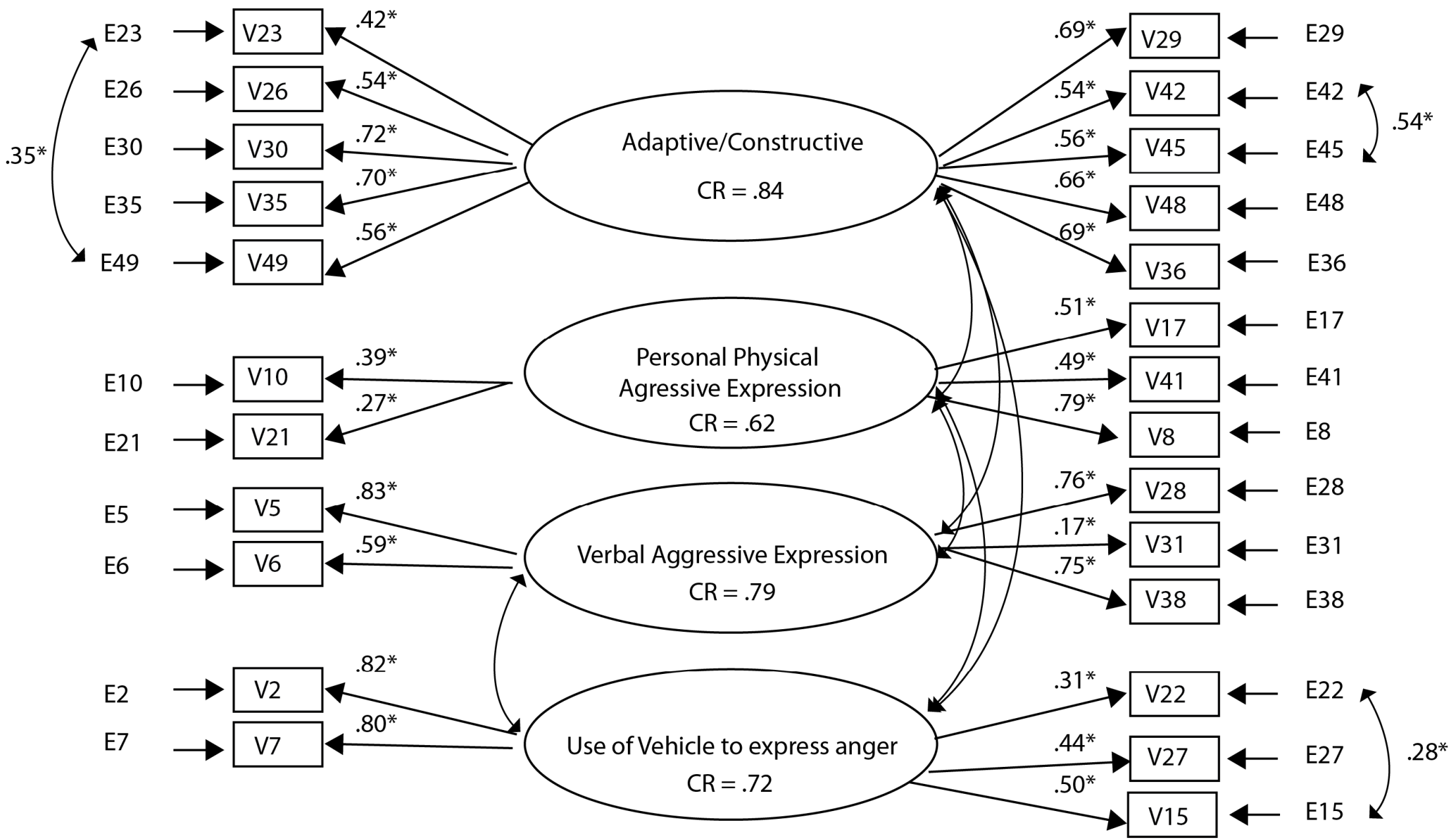


Figure 1: Confirmatory Factor Analysis of DAX_25 items 
2017-05-25

\section{Gender roles, sex and the expression of driving anger}

Sullman, Mark J. M.

Elsevier

M.J.M. Sullman, J. Paxion, A.N. Stephens, Gender roles, sex and the expression of driving anger, Accident Analysis \& Prevention, Volume 106, September 2017, Pages 23-30

http://dx.doi.org/10.1016/j.aap.2017.05.016

Downloaded from Cranfield Library Services E-Repository 